\title{
Restoration of lymphatic function rescues obesity in Prox1-haploinsufficient mice
}

\author{
Noelia Escobedo, ${ }^{1}$ Steven T. Proulx, ${ }^{2}$ Sinem Karaman, ${ }^{2}$ Miriam E. Dillard, ${ }^{1}$ Nicole Johnson, ${ }^{1}$ \\ Michael Detmar, ${ }^{2}$ and Guillermo Oliver ${ }^{1}$ \\ 'Department of Genetics, St. Jude Children's Research Hospital, Memphis, Tennessee, USA. \\ ${ }^{2}$ Institute of Pharmaceutical Sciences, Swiss Federal Institute of Technology, ETH Zurich, Zurich, Switzerland.
}

Prox1 heterozygous mice have a defective lymphatic vasculature and develop late-onset obesity. Chyle abnormally leaks from those vessels, accumulates in the surrounding tissues, and causes an increase in adipose tissue. We characterized the lymphatics of Prox $^{1^{+/-}}$mice to determine whether the extent of obesity correlated with the severity of lymphatic defects. The lymphatic vasculature in $\mathrm{Prox}^{+/-}$mice exhibited reduced tracer clearance from the ear skin, dysfunctional perfusion of the lower legs, and reduced tracer uptake into the deep lymphatic collectors during mechanostimulation prior to the onset of obesity. Ear lymphatic vessels and leg collectors in $\mathrm{Prox}^{+/-}$mice were disorganized and irregular, further confirming that defective lymphatic vessels are associated with obesity in $\mathrm{Prox}^{1^{+/}-}$mice. We now provide conclusive in vivo evidence that demonstrates that leaky lymphatics mediate obesity in $\mathrm{Prox}^{1^{+/-}}$mice, as restoration of lymphatic vasculature function was sufficient to rescue the obesity features in $\mathrm{Prox}^{1^{+/}-}$mice. Finally, depth-lipomic profiling of lymph contents showed that free fatty acids induce adipogenesis in vitro.

Authorship note: N. Escobedo, S.T. Proulx, and S. Karaman contributed equally to this work.

Conflict of interest: The authors have declared that no conflict of interest exists.

Submitted: October 12, 2015 Accepted: January 22, 2016 Published: February 25, 2016

Reference information: JCI Insight. 2016;1(2):e85096. doi:10.1172/jici.nsight.85096.

\section{Introduction}

The lymphatic vasculature is a complex network of lymphatic vessels that maintains body fluid homeostasis, lipid transport, and immune cell trafficking. Malfunction of the lymphatic vasculature can result in lymphedema, a chronic condition caused by excessive accumulation of protein-rich fluid in interstitial spaces. Lymphedema can be the consequence of a genetic defect (primary lymphedema) or injury to the lymphatic vasculature (secondary lymphedema) as a result of surgery, infection, or radiation therapy (1-3). The main features of lymphedema include swelling of the extremities, tissue fibrosis, susceptibility to infections, and accumulation of subcutaneous fat $(1,2,4)$. Recent data support the view that impaired lymph drainage also causes changes in the immune and inflammatory responses, dysregulation of body fluid homeostasis, disturbances of lipid metabolism and transport, and alterations in the extent of cancer metastasis and obesity (5-7).

The number of obese individuals is rising at an alarming rate; according to the World Health Organization, obesity is now considered a 21st-century global epidemic. Currently, the worldwide prevalence of overweight individuals is $39 \%$ of adults (8). More than 1.9 billion people are overweight, and more than 600 million people are obese (8); further, diseases associated with obesity are the second-leading cause of death in the US (9). Moreover, obesity poses a major public health threat because it is a key risk factor for metabolic and cardiovascular diseases (e.g., type 2 diabetes, hypertension, and stroke, among others) $(10,11)$. Initially explained as a consequence of excessive dietary intake or inadequate energy utilization, it is now clear that additional factors (e.g., genetic inheritance, hormonal disorders, and aging) also contribute to obesity. Despite some well-established connections between lymphatic function and lipid absorption and transport, the role of the lymphatic vasculature in adipose metabolism has only recently been recognized $(12,13)$, and it is known that chronic lymphedema leads to adipose tissue accumulation in the affected area $(14,15)$. Surgeons have indicated that, in lymphedema, the excess fluid is accompanied by "wet fat" (16) and that "lymphedema is clinically characterized by progressive fat deposition and tissue fibrosis" (4). Edema has also been associated with marked lipid accumulation. For example, hypercholesterolemic apolipoprotein E-deficient $\left(\right.$ Apoe $\left.^{--}\right)$mice develop structural and functional abnormalities of the lymphatic vasculature and exhibit peripheral edema associated with hypercholesterolemia (17), and amelioration of lymphatic drainage reduces the cholesterol and lipid accumulation in $A p o e^{-1-}$ mice (18). Additionally, an abnormal lymphoscintigraphic pattern, with a slowing of lymphatic flow, has been reported in patients suffering from lipedema, a chronic disease of lipid metabolism characterized 



Figure 1. Reduced clearance of lymphatic tracer after ear injection in young and old Prox1+- mice. (A and B) Weight distribution in young (2-3 months of age) (A) and old (5-10 months of age) (B) WT and Prox ${ }^{+/-}$mice. (C and D) Quantification of half-life of P20D800 dye in young (C) and old (D) WT and Prox $1^{+/-}$mice. (E and $\mathbf{F}$ ) Clearance rate (K rate) of P20D800 dye, as a measure of lymphatic ear clearance, in young (E) and old (F) WT and Prox $7^{+/-}$mice. ${ }^{*} P \leq 0.05 ;{ }^{* *} P \leq 0.0001,2$-tailed Student's $t$ test.

by bilateral and symmetric lower-extremity fat deposition (19). Moreover, in sustained cases of lipedema, the lymph vessels are unable to function, and lymph fluid accumulates (lympholipedema) (20).

We previously provided some of the first in vivo evidence linking lymphatic malfunction and obesity in an animal model (7). We showed that $P r o x 1^{+/-}$mice with a defective lymphatic vasculature develop features characteristic of late-onset obesity and determined that obesity in Prox $^{+/-}$mice is not a consequence of changes in food intake, energy expenditure, or dysregulation of appetite. Instead, this unique phenotype was most likely caused by subcutaneous and intra-abdominal fat accumulation, resulting from the subtle leakage of chyle (the lipid-rich fluid transported by lymphatic vessels of the small intestine) from defective lymphatics (7). Moreover, we showed that chyle promotes adipogenic differentiation of mouse 3T3-L1 preadipocytes in culture (7).

In the present study, we extended those initial analyses by performing a detailed characterization of the morphological and functional defects of the lymphatic vasculature of Prox $1^{+/-}$mice before and after the onset of obesity to determine whether the severity of those alterations is correlated with the extent of obesity. More importantly, we show that restoration of lymphatic function was sufficient to ameliorate the obesity phenotype and related metabolic alterations in Prox $1^{+/-}$mice. Finally, we used a combination of biochemical approaches to identify the adipogenic factor present in chyle.

\section{Results}

Prox $1^{+/-}$mice have slower tracer clearance by ear lymphatic vessels. We previously reported that most Prox $1^{+/-}$ mice die at birth or a few days thereafter due to chylous ascites and/or chylothorax (7). The surviving Prox $1^{+/-}$mice develop features of adult-onset obesity, starting at around 4 months of age, due to subtle lymphatic vascular leakage (7). To investigate the association between the extent of obesity and the severity of lymphatic vasculature defects and malfunction in $\mathrm{Prox}^{+/-}$mice, we first evaluated lymphatic function in Prox $^{+/-}$mice before the onset of obesity (in mice younger than 3 months) and after (in mice older than 5 months) (Figure 1, A and B).

Initially, we evaluated functional features by using an in vivo ear lymphatic clearance assay. To do this, a lymphatic-specific tracer was injected into each ear, and its clearance was measured at different time points, as 
Table 1. Ear lymphatic clearance assay results

\begin{tabular}{lcccccc}
\hline Age group & \multicolumn{3}{c}{ WT } & \multicolumn{3}{c}{ Prox1 $^{+/-}$} \\
& $\mathrm{t}_{1 / 2}(\mathrm{~h})$ & $\mathrm{K}(\mathrm{ml} / \mathrm{min})$ & $n$ & $\mathrm{t}_{1 / 2}(\mathrm{~h})$ & $\mathrm{K}(\mathrm{ml} / \mathrm{min})$ & $n$ \\
Young $(2-3 \mathrm{mo})$ & 3.70 & 0.1985 & 8 & 5.36 & 0.1417 & 8 \\
Old $(5-8 \mathrm{mo})$ & 3.91 & 0.1977 & 11 & 5.90 & 0.1402 & 13 \\
K, clearance rate; mo, months; $t_{1 / 2}$, half-life. & & & \\
\hline
\end{tabular}

previously described $(21,22)$. Comparison of the half-life $\left(t_{1 / 2}\right)$ and the rate of clearance (K rate) of the tracer in young WT mice (mean $t_{1 / 2}=3.70 \pm 0.26 \mathrm{~h} ; n=8$ ) versus Prox ${ }^{+/-}$littermates (mean $t_{1 / 2}=5.36 \pm 0.53 \mathrm{~h} ; n=8$ ) (Table 1) demonstrated that lymphatic vasculature function was impaired in Proxl $^{+/-}$mice before the onset of obesity (Figure 1, C and E). This decrease in lymphatic function was also observed in older obese Prox ${ }^{+/-}$mice (WT mean $t_{1 / 2}=3.91 \pm 0.37 \mathrm{~h} ; n=11 ; \operatorname{Prox}^{+/-}$mean $t_{1 / 2}=5.90 \pm 0.70 ; n=13$ ) (Figure 1, D and F, and Table 1).

Impaired function of the collecting lymphatic vessels in Prox $1^{+/}$mice. To characterize collecting lymphatic vessel function in Proxi ${ }^{+/-}$mice before and after the onset of obesity, we assessed the function of lower hind leg collecting vessels by using noninvasive near-infrared (NIR) imaging as previously described (23) (Figure 2A). Using this approach and following the injection of the P20-D680 tracer, we identified an abnormal lymphatic network in the lower legs of young and old Prox ${ }^{+/-}$mice that was characterized by dysfunctional perfusion into the dermal network, with dermal backflow, interstitial leakage, and misrouting of flow evident (Figure 2, B-D, and Supplemental Videos 1 and 2; supplemental material available online with this article; doi:10.1172/jci.insight.85096DS1). These defects were observed in every Prox $1^{+/-}$mouse (young and old). Among the older Prox $1^{+/-}$mice, the magnitude of lymphatic malfunction appeared to be related to the extent of obesity, i.e., the heaviest Prox $1^{+/-}$mice exhibited the most severe lymphatic phenotype (Supplemental Figure 1).

To measure the contraction rate in the collecting vessels, we quantified the contraction frequency of the afferent collecting lymphatic vessels near their entry into the popliteal lymph nodes (24). The contraction rate of collecting lymphatic vessels in young WT mice exhibited a mean rate of $14.92 \pm$ 0.69 contractions $/ \mathrm{min}$. Surprisingly, this rate did not significantly differ from that of young nonobese Prox $^{+/-}$littermates $(13.93 \pm 0.58$ contractions/min) (Figure $2 \mathrm{E})$. However, irregular collecting lymphatic vessel contraction frequencies were detected in older obese $P r o x 1^{+/-}$mice, with contraction frequencies significantly lower than their WT controls $(11.30 \pm 1.27$ contractions/min vs. $15.84 \pm 0.56$ contractions/ $\min ; P=0.0036$ ) (Figure $2 \mathrm{~F}$ ).

To further characterize lymphatic function in $P r o x 1^{+/-}$mice before and after the onset of obesity, we determined the response to an acute tracer load within afferent collectors in the lower leg during mechanostimulation at the injection site as described before (24). NIR imaging of the lymphatic vasculature revealed that collecting vessels in nonobese young or old WT mice respond to intermittent mechanostimulation with a rapid increase in the tracer perfusion, followed by clearance of the tracer over time (Supplemental Figure 2A). Additionally, there was no difference in the fluorescence intensity of the dye in basal conditions (Supplemental Figure 2, before mechanostimulation and indicated by arrows). In contrast, the increase in signal after mechanostimulation of young (nonobese) or old (obese) $P$ rox $1^{+/-}$mice was significantly reduced after mechanostimulation compared to that in WT mice (1.47-fold increase in young WT vs. 1.05 -fold increase in young $P$ rox1 $1^{+/-}, P<0.0001 ; 1.59$-fold increase in old WT vs. 1.07 -fold increase in old Prox $1^{+/-}, P=$ 0.0033) (Figure 2, G and H, and Supplemental Figure 2B). This result indicated that Prox $1^{+/-}$mice have less efficient uptake into the deep collectors during mechanostimulation and that, instead of being efficiently transported into the collectors, the tracer instead perfused into dermal vessels or leaked into the interstitium (Figure 2, B-D). Together, these results argue that the lymphatic vasculature in Prox $^{1^{+-}}$mice is functionally impaired, and, although some aspects of this are already evident in younger animals before the onset of obesity, they increase in severity in older, fatter animals.

Analysis of lymphatic function in obese ob/ob mice. It has been described previously that high-fat diet-promoted (HFD-promoted) obesity affects lymphatic function (24-26), and recent clinical data indicate that lymphatic drainage is reduced in obese subjects compared to lean subjects, suggesting that obesity also impairs lymphatic function (27). To evaluate this possibility and to gain insight about whether some of 

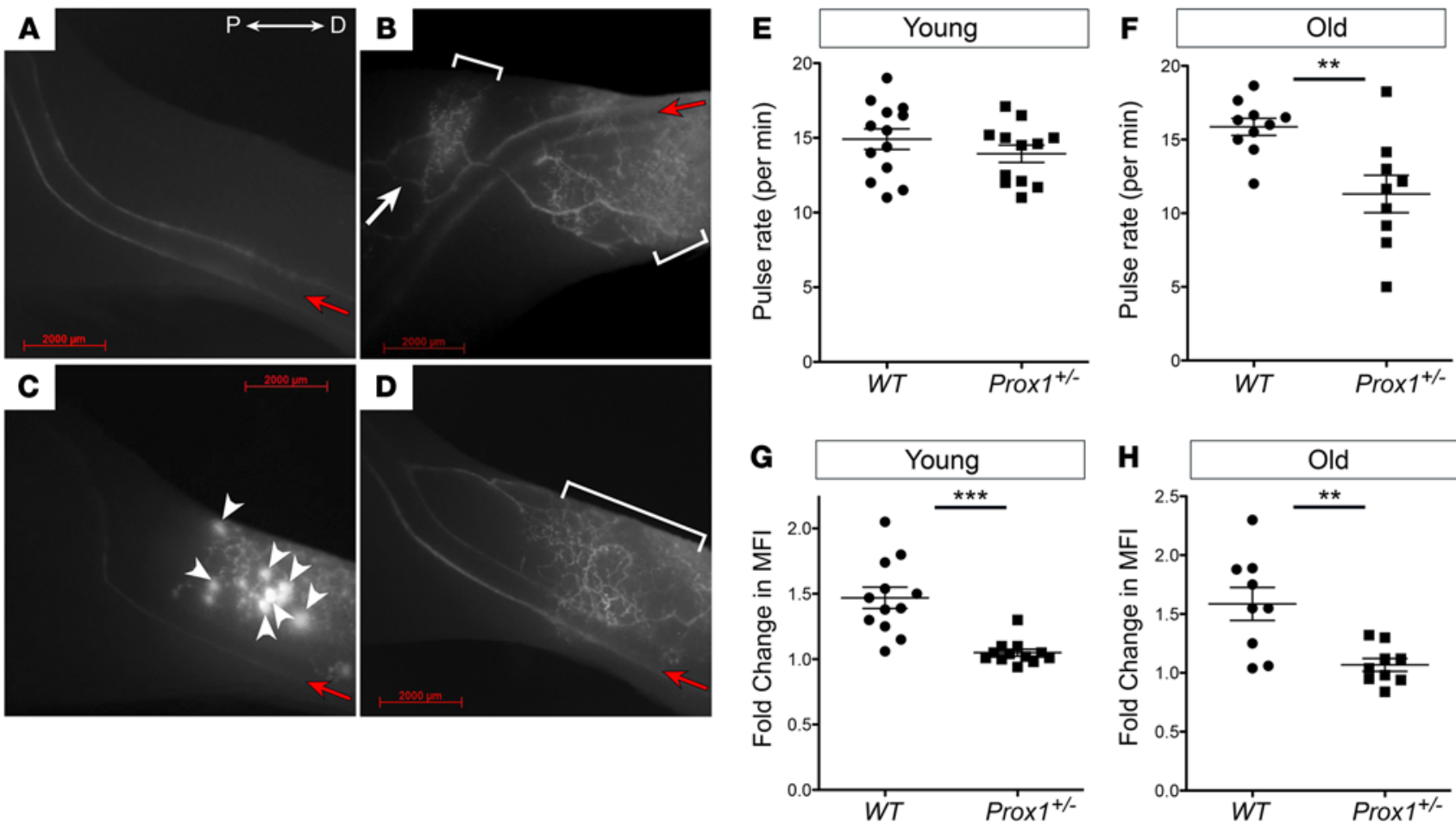

Figure 2. Collecting lymphatic vessel function in the lower limbs. (A-D) Near-infrared fluorescence imaging of the normal lower limb lymphatic network in WT mice (A) and three representative images of the phenotype seen in Prox1 ${ }^{+/-}$mice (B-D). Three phenotypes are consistently observed in all Prox 1 heterozygous mice: dermal backflow (brackets), collateral rerouting (white arrow), and interstitial leakage (arrowheads). All the pictures are oriented in the same direction, where $P$ is proximal and $D$ is distal to the popliteal lymph node. Red arrows indicate the direction of the flow. (E and $\mathbf{F}$ ) Collecting vessel contractility in young (E) and old (F) WT and Prox $1^{+/-}$mice. No difference was seen between young WT and Prox $1^{+/-}$mice, but contractility was significantly reduced in old Prox $1^{+-}$mice. (G and $\left.\mathbf{H}\right)$ Response to mechanostimulation in young (G) and old $(\mathbf{H})$ WT and Prox $1^{+/-}$mice. Young and old Prox $1^{+/-}$ mice had less efficient uptake into deep collectors after mechanostimulation. MFI, mean fluorescence intensity. ${ }^{* *} P \leq 0.01 ;{ }^{* * *} P \leq 0.0001,2$-tailed Student's $t$ test. Scale bar: $2,000 \mu \mathrm{m}$.

the functional defects observed in the lymphatic vasculature of Prox $1^{+/-}$mice are secondary to the obesity phenotype (or are at least partially responsible for the weight gain), we analyzed lymphatic function in a typical genetic model of obesity. Mice that are homozygous for a spontaneous inactivating mutation in leptin (Lep ${ }^{o b / o b}$ mice, commonly referred as $o b / o b$ mice) represent a genetic model of severe obesity (28). We thought that this strain could be a useful model to use for comparison with the Prox1 ${ }^{+/-}$mice in order to help us discriminate features that are general hallmarks of obesity versus those that could be more specific to a lymphatic leakage model of obesity.

As before, we divided the mice into young (4 months of age) and adult ( 8 months of age) groups and performed sequential NIR imaging after injection of tracer to evaluate ear lymphatic clearance. $o b / o b$ mice gained significantly more weight than WT mice after weaning $(61.64 \pm 3.20 \mathrm{~g}$ vs. $30.64 \pm 2.09 \mathrm{~g}, P<$ 0.0001) (Supplemental Figure 3A). The ear lymphatic clearance assay revealed that, unlike Prox $1^{+/-}$mice, $o b / o b$ mice showed normal transport in dermal lymphatics in both young $\left(t_{1 / 2}=3.73 \pm 0.26 \mathrm{~h}\right.$ in ob/ob vs. $3.78 \pm 0.22 \mathrm{~h}$ in WT, $P=0.88$; Supplemental Figure 3, B and C) and overweight adult $o b / o b$ mice (93.82 \pm $7.24 \mathrm{~g}$ vs. $35.01 \pm 3.20 \mathrm{~g}$ in WT, $P=0.0003$; Supplemental Figure $3 \mathrm{D})\left(t_{1 / 2}=4.17 \pm 0.30 \mathrm{~h}\right.$ in $o b / o b$ vs. 3.56 $\pm 0.26 \mathrm{~h}$ in WT, $P=0.18$ ) (Supplemental Figure $3, \mathrm{E}$ and $\mathrm{F}$ ).

Next, we investigated whether obesity affects larger-caliber lymphatic vessels by performing functional tests in the lower-limb collectors similar to those described above. NIR imaging revealed no dermal backflow or interstitial leakage in young or old $o b / o b$ mice after injection of the lymphatic tracer into the paw skin (Supplemental Figure 3, I and J, and data not shown). Some collecting lymphatic vessels close to the popliteal node appeared dilated in the $o b / o b$ mice (Supplemental Figure 3J, arrow), a result similar to what has been previously described in mice fed a HFD (24); however, overall, the perfusion of the lymphatic vessels looked similar to that of the WT littermates and differed from that of $P$ rox $1^{+/-}$mice, in which lymphatic leakage and malfunction were evident. 


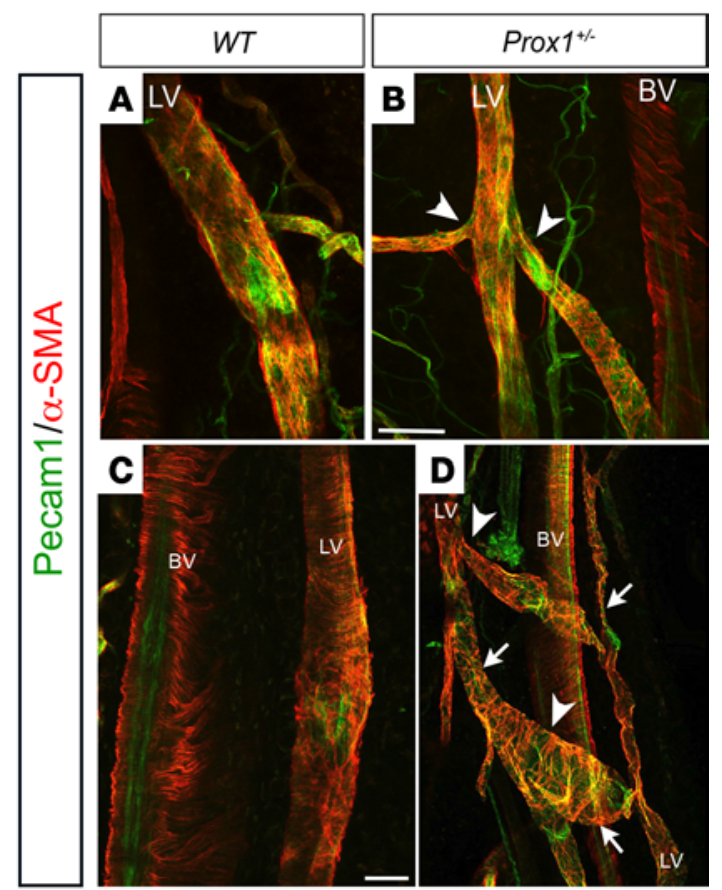

Figure 3. Patterning defects in collecting vessels of the hind limbs of Prox $\mathbf{1}^{+/-}$mice. The lymphatic vasculature in young (A and $\mathbf{B})$ and old (C and $\mathbf{D})$ WT $(\mathbf{A}$ and $\mathbf{C})$ and $\operatorname{Prox}^{+/-}(\mathbf{B}$ and $\mathbf{D})$ mice was disorganized, exhibited irregular diameter (arrows in $\mathbf{D}$ ), and had multiple branches (arrowheads in $\mathbf{B}$ and $\mathbf{D})$. Pecam1, platelet endothelial cell adhesion molecule 1; $\alpha$-SMA, $\alpha$-smooth muscle actin; BV, blood vessel; LV, lymphatic vessel. Scale bar: $100 \mu \mathrm{m}$.

As an additional test, we measured the contraction frequency in collecting vessels of young and old $o b / o b$ mice compared to WT littermates. Differences in contraction rates were detected in young $o b / o b$ mice compared to those in WT littermates $(10.49 \pm 0.67$ contractions $/ \mathrm{min}$ vs. $14.21 \pm 0.66$ contractions $/ \mathrm{min}$, $P=0.0022$, respectively) (Supplemental Figure 3K), and this difference was more significant in older $o b / o b$ mice (8.05 \pm 0.56 contractions/min vs. $14.52 \pm 0.66$ contractions $/ \mathrm{min}$ in old WT, $P<0.0001$ ) (Supplemental Figure $3 \mathrm{~L})$. A small reduction in contractility of the large-caliber lymphatic vessels was observed in the old severely obese $o b / o b$ mice compared to the younger $o b / o b$ mice $(P=0.048)$. We observed no obvious differences in perfusion in young or old $o b / o b$ mice after mechanostimulation (data not shown). These results indicate that the severe obesity in $o b / o b$ mice affects collecting vessel contractility but does not result in dermal backflow or interstitial leakage.

Taken together, the above results confirm that (a) $o b / o b$ mice fed a regular diet represent an obesity model without major lymphatic vasculature defects and (b) the functional defects seen in Prox $1^{+/-}$mice are not present in $o b / o b$ mice (ear clearance, dermal backflow, and response to an acute load of tracer in the lower legs). Therefore, those phenotypes are due to defects in overall lymphatic function and not the obesity phenotype seen in Proxi ${ }^{+/-}$mice.

Morphologic alterations in lymphatic vessels in Prox $1^{+/-}$mice are present before the onset of obesity. We next evaluated how the functional lymphatic impairment in young and old $P r o x 1^{+/-}$mice correlated with morphologic changes in the lymphatic vasculature. To do this, we analyzed the ear dermal lymphatics and lower leg collecting lymphatics via whole-mount immunostaining. Adult mouse ear skin vessels were stained with antibodies against lymphatic vessel endothelial hyaluronan receptor 1 (Lyve-1) and platelet endothelial cell adhesion molecule 1 (Pecam1, also known as CD31). Ear lymphatic capillaries exhibited a normal continuous network in WT mice, whereas they formed a defective network in Prox $1^{+/-}$mice (Supplemental Figure 4A). Furthermore, at higher magnification, it was evident that the integrity of some vessels was compromised in Prox $^{+/-}$mice (Supplemental Figure 4B, arrows), a result that supports our previous findings that the mesenteric lymphatic vessels are leaky in these animals (7). Moreover, immunostaining for the tight junction protein zonula occludens-1 (ZO-1) showed that the connections between endothelial cells that compose the lymphatic vessel were damaged and/or lost in Prox $1^{+/-}$mice (Supplemental Figure 4C, dotted line and arrow). These gaps most likely disrupt the integrity of the vessel (manifested by ruptured vessels) and may explain the dye leakage observed in the functional analyses. 

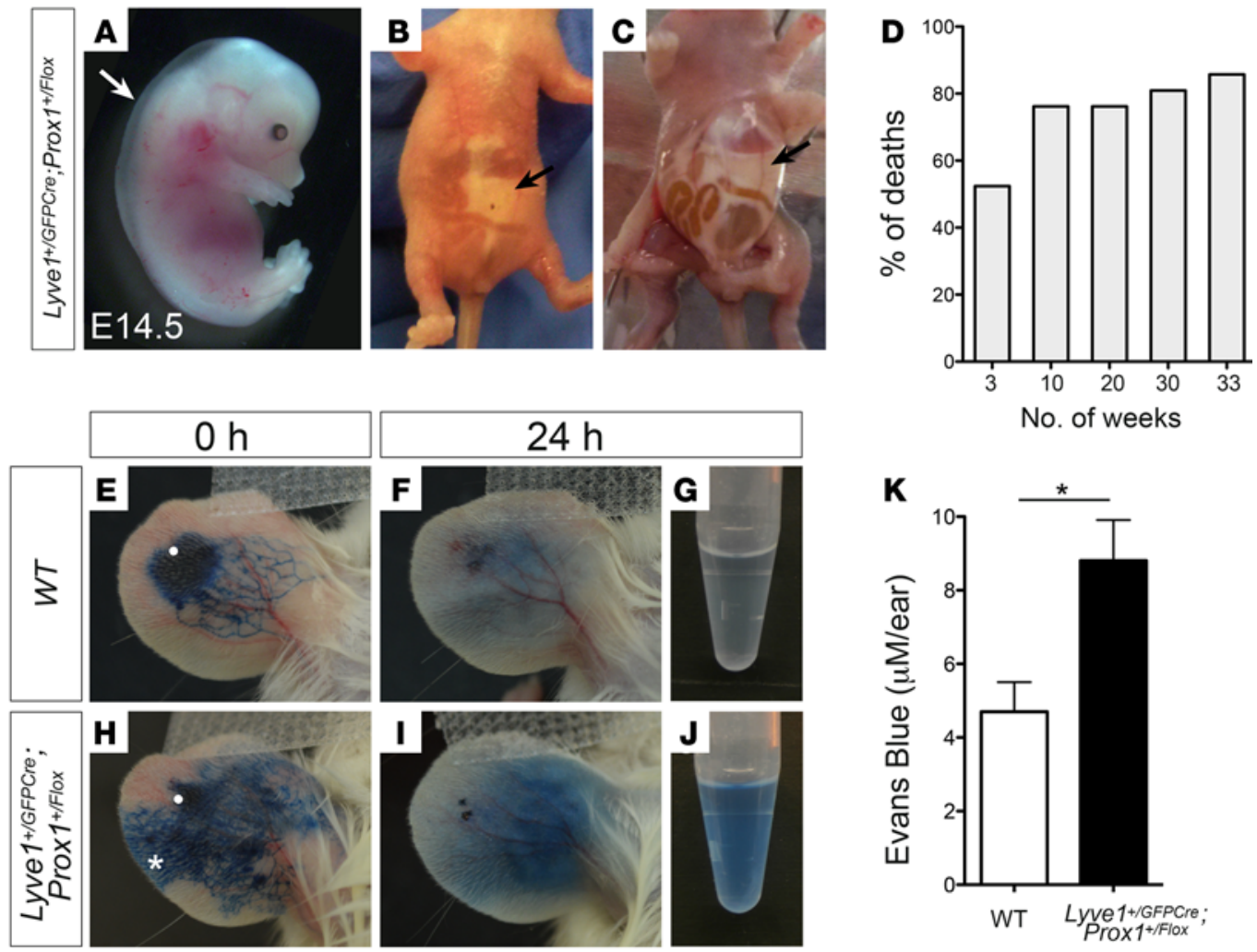

Figure 4. Conditional Prox1 mice frequently die prematurely and display defects in lymph flow. (A) E14.5 Lyve $1^{+/ C F P C r e} ;$ Prox $7^{+/ F l o x}$ embryos consistently exhib-

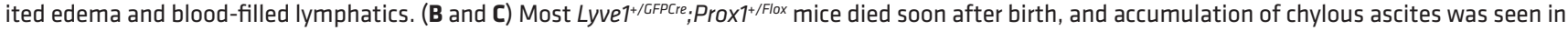

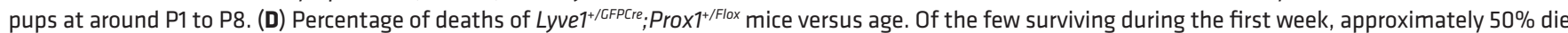
before weaning ( 3 weeks of age). (E-K) Among those few surviving pups (10-33 weeks of age), Evans blue visual lymphangiography and subsequent quantification was performed to follow lymph drainage patterns. Evans blue injection into the dermis of the ear of a WT mouse (injection site is marked by a white dot) resulted in unidirectional drainage and convergence of the dye into lymphatic collecting vessels (E). Retrograde lymph flow (marked by an asterisk) and increased lateral spread occurred when Evans blue dye was injected into the ear of a Lyve $1^{+/ C F P C r e}$;Prox $7^{+/ F l o x}$ mouse $(\mathbf{H})$, and increased retention was seen after

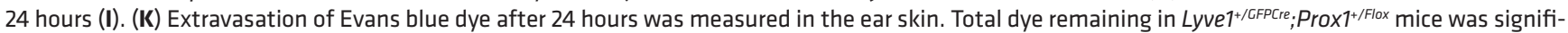

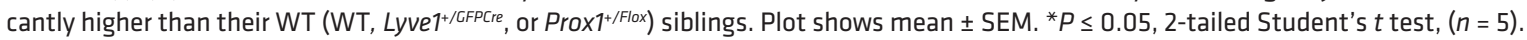

A similar morphologic analysis was performed on the collecting vessels of the hind leg using anti-Pecam1 and anti- $\alpha$-smooth muscle actin ( $\alpha$-SMA) antibodies. Collecting lymphatic vessels were well organized and had regular lumens in WT mice (Figure 3, A and C). Conversely, collector vessels in Prox $1^{+/}$ mice formed a dense, irregular, and abnormal-looking network and were frequently irregular and dilated (Figure 3, B and D). This abnormal architecture of lymphatic vessels in $P r o x 1^{+/-}$mice was evident in young and old mice and corresponds to collecting vessels with a tortuous and irregular pattern and frequently displayed "buds" and interconnections between the two collectors around the popliteal vein (Figure 3D, arrowheads). These phenotypes are consistent with the observed functional defects, i.e., the leakage and abnormal rerouting of the injected dye seen in $\mathrm{ProxI}^{+/-}$mice during the functional analysis. Moreover, the morphologic changes included alterations of vessel caliber; the collateral vessels were irregular, with constricted and dilated areas (Figure 3D, arrows). These alterations were not seen in $o b / o b$ mice (data not shown). No major differences were observed in the $\alpha$-SMA coverage in Prox ${ }^{+/-}$mice (Figure 3).

Mice with lymphatic-specific Prox1 deletion frequently die prematurely and display chylous ascites and defects in lymph flow. To conclusively demonstrate that lymphatic malfunction is the main cause of obesity in Prox 1 heterozygous mice, we deleted Prox1 specifically in lymphatic endothelial cells (LECs). To do this, mice carrying Prox 1 flanked by a loxP site $\left(P r o x 1^{+/ F l o x}\right)(7)$ were crossed with a mouse line in which Cre recombinase and enhanced green fluorescent protein (EGFP) expression is driven by the Lyve-1 promoter (Lyve ${ }^{+/ G F P C r e}$ ). This mouse line has been described before and has excision efficiency greater than $90 \%$ in LECs (29). The lymphatic abnormalities of Lyve1 ${ }^{+/ G F P r e}$ Prox $1^{+/ F l o x}$ animals were the same as those of Prox $1^{+/-}$mice. At E14.5, Lyve $1^{+/ G F P C r} ;$ Prox $1^{+/ F l o x}$ embryos had edema (Figure 4A), and most of those pups died within a few days of 
Table 2. Low survival in Lyve1+/GFPre;Prox1+/Flox conditional mice

\begin{tabular}{lcc} 
Genotype & \multicolumn{2}{c}{ Pups alive at P10 } \\
& Number & Percentage \\
WT & 67 & $29.78 \%$ \\
Lyve1+/GFPCre & 65 & $28.89 \%$ \\
Prox $^{+/ \text {Flox }}$ & 72 & $32.00 \%$ \\
Lyve1 $^{+/ \text {GPCre } ; \text { Prox1+/Flox }}$ & 21 & $9.33 \%$ \\
Total (26 litters) & 225 & $100 \%$
\end{tabular}

birth and had peritoneal chylous ascites (Figure 4, B and C, arrows). To date, with a total of 255 animals in 26 litters, only 21 (9.33\% instead of the expected 25\%) Lyve1 ${ }^{+/ G F P r e} ;$ Prox $1^{+/ F l o x}$ newborn pups survived the first week of life (Table 2). Moreover, the $\sim 47 \%$ that survived the first week of life died at around weaning age (Figure 4D), and the rest of the Lyve $1^{+/ G F P C r} ;$ Prox $1^{+/ F l o x}$ mice that survived after weaning died suddenly and prematurely in the following weeks, with approximately $76 \%$ of the deaths occurring before 10 weeks of age (Figure 4D). To assess lymphatic function in Lyve $^{+/ G F P C r e} ;$ Prox $1^{+/ F l o x}$ mice, we performed Evans blue visual lymphangiography to follow lymph drainage patterns. We intradermally injected $3 \mu 1$ of $1 \%$ Evans blue dye into the ear skin of WT and Lyve1 ${ }^{+/ G F P r e}$ Prox $1^{+/ F l o x}$ littermates as described before $(30,31)$. Ears were photographed 0 and 24 hours after dye injection (Figure 4, E, F, H, and I). After 24 hours, mice were euthanized, ears were removed, and the remaining Evans blue dye was extracted for an additional 48 hours and quantified as described before (refs. 30-32 and Figure 4, G, J, and K). All Lyve $1^{+/ \text {GFPCre }} ;$ Prox $1^{+/ \text {Flox }}$ mice showed an increased lateral spread of Evans blue dye during the injection (Figure $4 \mathrm{H}$, asterisk) and retained a larger amount of dye (Figure 4, I-K), a result indicative of defective lymphatic drainage. These results indicate that specific Prox1 deletion from LECs is sufficient to recapitulate the lymphatic defects observed in standard Prox1 heterozygous mice.

In vivo restoration of lymph function defects rescues the obesity phenotype in Prox $1^{+/-}$mice. To further demonstrate that lymphatic malfunction is a leading cause of obesity in $P r o x 1^{+/-}$mice, we decided to use an in vivo gain-of-function approach. To do this, we initially evaluated whether specific restoration of Prox1 levels in Prox $1^{+/-}$LECs was sufficient to rescue the lymphatic alterations described in these mice. Then, if restoring Prox1 levels rescues the lymphatic defects, we should be able determine whether the obesity phenotype is also ameliorated in these mice. As part of this approach, we used the transgenic mouse strain Jojo-Prox1, which expresses Prox1 in a time- and tissue-specific manner after Cre recombination $(33,34)$. To restore Prox1 levels in LECs, we initially crossed Jojo-Prox1 mice with Prox ${ }^{+/ L a c Z}$ mice to generate the Jojo-Prox1; Prox $1^{+/-}$compound mice. Those mice were posteriorly breed with $L y v e 1^{+/ G F P C r e}$ mice to generate Lyve ${ }^{+/ G F P C r e}$; Jojo-Prox1;Prox $1^{+/-}$mice.

Table 3. Postnatal viability at P10 to P14 of different genotypes generated from Jojo-Prox1;Prox1+/- x Lyve1+/GFPCre crosses

\begin{tabular}{|c|c|c|}
\hline \multirow[t]{2}{*}{ Genotype } & \multicolumn{2}{|c|}{ Surviving pups } \\
\hline & Number & Percentage \\
\hline WT & 33 & $10.25 \%$ \\
\hline Jojo-Prox1 & 61 & $18.94 \%$ \\
\hline LyVe 1+/GFPCre & 58 & $18.01 \%$ \\
\hline Prox $1^{+/-}$ & 12 & $3.73 \%$ \\
\hline Lyve1+/GFPCre;jojo-Prox1 & 59 & $18.32 \%$ \\
\hline Lyve1 1/GFPCre $_{\text {Proxit-- }}$ & 15 & $4.66 \%$ \\
\hline Jojo-Prox1;Prox11/- & 20 & $6.21 \%$ \\
\hline 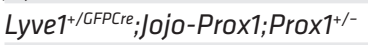 & 64 & $19.88 \%$ \\
\hline Total & 322 & $100 \%$ \\
\hline
\end{tabular}





M


Figure 5. Lymphatic-specific Prox1 restoration rescues the adult-onset obesity phenotype in Prox $\mathbf{1}^{+-}$- mice. (A) Average body weight of littermate mice measured every week, starting at weaning age. Progressive weight gain was observed in Prox $7^{+-}$mice (red dots), but no significant weight gain, compared to that of WT mice

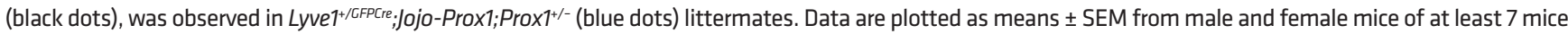
per genotype. (B and C) Leptin (B) and insulin (C) levels were higher in adult Prox1 mice than WT counterparts; however, in Lyve1 ${ }^{+/ C F P C r e}$;ojo-Prox 1;Prox $1^{+/-}$mice, the levels were comparable to their WT littermates. (D-M) Rescue of ear lymph flow. Representative photographs of ears at 0 and 24 hours after injection of Evans blue

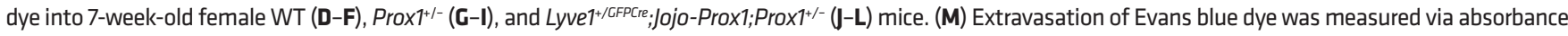
at $620 \mathrm{~nm}$. Quantification of the total dye remaining in the ear skin for each genotype shows that the lymph flow defect seen in Prox ${ }^{+1-}$ mice was improved in

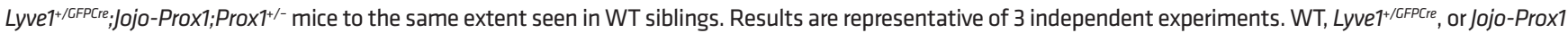
mice were used as WT control mice. Plot shows mean \pm SEM. ${ }^{*} P \leq 0.05$; ${ }^{* *} P \leq 0.01 ;{ }^{* *} P \leq 0.001$, 1-way ANOVA followed by Bonferroni's multiple comparison test.

To determine the success of this approach, we examined the rate of survival of Lyve1+/GFPCre; Jojo-Prox1; Prox $1^{+/-}$animals compared with that of Prox $^{+1-}$ littermates. As mentioned before, most Prox $1^{+/-}$newborns die at birth or a few days thereafter as a consequence of chylothorax or chylous ascites (7). None of the


the pups exhibited chylous ascites or chylothorax (data not shown), indicating that restoring the levels of Prox1 in LECs was sufficient to rescue at least some of the most severe embryonic lymphatic defects. Additionally, the survival rate of $L y v e 1^{+/ G F P C r} ;$ Jojo-Prox1;Prox $1^{+/-}$mice was much better than the severely reduced survival rate of Prox $1^{+/}$littermates. At P10 to P14, there were 322 surviving pups: 12 (3.73\%) were Prox1 $1^{+/}$ and 64 (19.88\%) were Lyve1 ${ }^{+/ G F P C r e} ;$ Jojo-Proxl;Prox1 ${ }^{+/-}$(Table 3). 
Next, we determined whether obesity was ameliorated in $L y v e 1^{+/ G F P C r e}$;Jojo-Prox1;Prox1 ${ }^{+/-}$littermates by weighing animals soon after weaning and then every week thereafter. The Lyve $1^{+/ \text {GFPCre }}$;ojo-Prox1;Prox $1^{+/-}$ mice did not show an abnormal weight gain with age. At 30 weeks, the average body weight of Prox $1^{+/-}$ mice was $68.25 \pm 1.25 \mathrm{~g}$; that of WT mice was $46.45 \pm 3.05 \mathrm{~g}$; and that of Lyve $1^{+/ \text {GFPCre }}$;ojo-Prox1;Prox $1^{+/-}$ mice was $50.57 \pm 3.06 \mathrm{~g}$ (Figure $5 \mathrm{~A}$ ).

Circulating levels of insulin and leptin have been shown to increase with obesity (35). We have previously shown that obese adult $\operatorname{Prox}^{+/-}$mice have consistently higher circulating levels of leptin and insulin than their WT littermates (7); therefore, we next compared the levels of circulating leptin and insulin in Lyve1 $1^{+/ \text {GFPre }}$;ojo-Prox 1;Prox $1^{+/-}$adult mice (4-8 months of age) as another feature of obesity. No substantial differences in the circulating levels of these proteins were observed in adult Lyve $1^{+/ \text {GFPCre }}$; Jojo-Prox1;Prox1 $1^{+-}$mice compared with their WT counterparts (Figure 5, B and C). This result suggested that lymphatic-specific Prox1 reestablishment is sufficient to rescue the obesity features seen in adult Prox $^{+/-}$adult mice.

To confirm that the rescue of the obesity phenotype was due to improved lymphatic function in Lyve $1^{+/ G F P C e}$;Jojo-Prox 1;Prox $1^{+/-}$mice, we intradermally injected $3 \mu 1$ of $1 \%$ Evans blue dye into the ear skin of WT, Prox1 $1^{+/-}$, and Lyve1 ${ }^{+/ G F P C r} ;$ Jojo-Prox1;Prox1 $1^{+/-}$littermates (4-7 weeks of age) as described above. Ears were photographed at 0 and 24 hours after dye injection (Figure 5, D, E, G, H, J, and K), and the remaining Evans blue dye was extracted after 24 hours (Figure 5, F, I, and L) and quantified (Figure 5M). The data consistently showed that, as expected, after 24 hours, the ears of Prox $^{+/-}$mice retained a large amount of dye (Figure 5, H, I, and M), a result indicative of defective lymphatic drainage. However, the amount of dye retained in ears of Lyve $1^{+/ G F P C r e}$; Jojo-Prox1;Prox ${ }^{+/-}$mice (Figure 5, K-M) was comparable to that of WT mice (Figure 5, E, F, and M), indicating an enhanced lymphatic clearance in Lyve $1^{+/ G F P C r e} ; \mathrm{Jo}_{-}$ jo-Prox $1 ;$ Prox $1^{+/-}$mice compared to the Prox $1^{+/-}$littermates.

To track the collecting vessels adjacent to the saphenous vein, we intradermally injected the hind limb footpads of WT, Prox1 ${ }^{+/-}$, and Lyve1 ${ }^{+/ G F P C r} ;$;ojo-Prox1;Prox1 ${ }^{+/-}$mice with Evans blue dye. As expected, the lymphatic network was defective in $P r o x 1^{+/-}$mice (Supplemental Figure 6B, white arrows and arrowheads); however, it appeared normal and similar to the WT network in Lyve1 ${ }^{+/ G F C r e}$;Jojo-Prox1;Prox1 ${ }^{+/-}$mice, with the two collecting vessels clearly seen along the lower legs (Supplemental Figure 6C). To determine whether Prox1 levels were restored in Lyve1 $1^{+/ G F P C e}$; Jojo-Prox1;Prox $1^{+/-}$mice, we measured Prox1 protein levels by Western blots. As seen in Supplemental Figure 5D, analysis of E14.5 dermal lymphatics shows a partial rescue of Prox1 levels in Lyve1 ${ }^{+/ G F P C r e}$; Jojo-Prox1;Prox $1^{+/-}$embryos.

These results show that restoring Prox1 levels in Lyve1 ${ }^{+/ G F P r e} ;$ Jojo-Prox1;Prox1 ${ }^{+/-}$LECs rescued at least some of their major lymphatic vasculature defects, resulting in increased survival and amelioration of obesity.

Free fatty acids are the adipogenic factor in chyle. Chyle contains triglycerides incorporating long-chain fatty acids. Disruption and/or obstruction of the intestinal lymphatic vasculature results in chylous ascites, due to the leakage of this fluid into the abdominal cavity (36). We previously demonstrated that Prox $1^{+/-}$ pups display subtle leakage of chyle into the surrounding tissues and this leakage most likely causes the obesity phenotype in these mice (7). Furthermore, we showed that chyle is adipogenic in vitro (7). Here, we evaluated whether that adipogenic property is a specific feature of chyle and whether lymph (inside the lymphatic vasculature) can exert the same adipogenic effect.

First, we obtained lymph from adult WT and Prox $^{+/-}$mice by direct cannulation of the thoracic duct. To investigate whether lymph promotes adipogenesis in vitro and whether WT and Prox $1^{+/-}$lymph exhibits different properties, we used the previously reported adipocyte differentiation assay (37). Mouse 3T3-L1 preadipocytes were maintained in culture under "control culture" conditions or with the addition of $4 \mu 1$ of lymph isolated from WT or Prox $1^{+/-}$mice. In this system, lymph had adipogenic properties similar to those of chyle (Supplemental Figure 7, A-D).

To identify the adipogenic factor(s) in chyle, we used the adipocyte differentiation assay with Oil Red $\mathrm{O}$ staining (an indicator of adipocyte differentiation). To evaluate whether such a factor could be a protein, we collected chyle from the abdominal cavities of newborn $P r o x 1^{+/-}$pups and heated it to $95^{\circ} \mathrm{C}$ for $30 \mathrm{~min}$ utes to denature all proteins. This treatment did not affect the adipogenic properties of chyle (Supplemental Figure 7E). Similar results were obtained when we subjected the samples to protease treatment with trypsin (Supplemental Figure 7F) or pepsin (Supplemental Figure 7G) as a second approach to inactivate proteins within the chyle. Together, these results showed that chyle retains its ability to trigger adipocyte differentiation in isolated preadipocytes upon removal of proteins (Supplemental Figure 7, E-G). 
Table 4. Percentage of free fatty acids found in WT and Prox ${ }^{1^{+-}}$adult mouse lymph by gas chromatography and mass spectrometry

\begin{tabular}{|c|c|c|}
\hline \multirow[t]{2}{*}{ Fatty acid } & \multicolumn{2}{|c|}{ Fatty acid in lymph (\%) } \\
\hline & Prox1 ${ }^{+/-}$ & WT \\
\hline Palmitic acid & 4.0 & 4.8 \\
\hline Palmitoleic acid & 4.2 & 4.9 \\
\hline Stearic acid & 0.3 & 0.5 \\
\hline Oleic acid & 53.0 & 49.5 \\
\hline Vaccenic acid & 0.8 & 1.2 \\
\hline Linoleic acid & 35.2 & 35.7 \\
\hline$\gamma$-Linolenic acid & 0.1 & 0.1 \\
\hline$\alpha$-Linolenic acid & 1.1 & 1.5 \\
\hline Dihomo- $\gamma$-linolenic acid & 0.1 & 0.1 \\
\hline Myristic acid & 0.2 & 0.3 \\
\hline Arachidonic acid & 0.5 & 0.6 \\
\hline Eicosapentaenoic acid & 0.2 & 0.2 \\
\hline Docosahexaenoic acid & 0.3 & 0.4 \\
\hline
\end{tabular}

Next, we separated the lipidic and protein fractions of chyle into organic and aqueous phases by using the Bligh-Dyer protocol (38) and tested each phase in vitro. As expected, the aqueous phase containing most of the proteins was not adipogenic (Supplemental Figure 7I); however, we detected substantial Oil Red $\mathrm{O}$ staining in the organic phase as well as in the combined organic and aqueous phases (Supplemental Figure 7, J and K). No Oil Red O staining was observed in the cells treated with DMSO, the vehicle for the organic-phase material (Supplemental Figure 7L). These data strongly suggested that the adipogenic factor in chyle was a lipid or group of lipids.

To identify the adipogenic lipid(s), we performed a complete lipid profile for samples of WT and Prox $1^{+1}$ lymph (obtained by cannulation of the thoracic duct). Lipidomic profiling of lymph showed that the lipid composition is mainly free fatty acids (data not shown). Additionally, as shown in Table 4, we detected no significant differences in the composition of free fatty acids in WT and Prox $1^{+/-}$lymph. Moreover, oleic and linoleic acid are the most abundant free fatty acids found in both lymph fluids. We then tested the 9 most abundant free fatty acids in the adipocyte differentiation assay at physiologically relevant concentrations. The 3T3-L1 cells were incubated for 2 days with each of the lipids and in the absence of dexamethasone and insulin. Of the 9 lipids tested, oleic acid, $\alpha$-linoleic acid, palmitoleic acid, and palmitic acid were highly adipogenic in vitro (Figure 6).

In summary, our results show that there are no differences in lipid composition in WT lymph versus Prox $1^{+/-}$lymph and, moreover, that free fatty acids in the lymph can induce adipogenesis in vitro. They also suggest that, in $P r o x 1^{+/-}$mice, the fatty acid fraction in the leaking chyle or lymph promotes de novo adipogenesis in the surrounding tissue, which ultimately results in obesity in adulthood.

\section{Discussion}

Using a wide array of morphological and functional assays, we determined that defects in the lymphatic vasculature of $\operatorname{Prox}^{1^{+-}}$mice precede the onset of obesity, which develops as these animals age. Prox1 conditional deletion in LECs (Lyve1 ${ }^{+/ \text {GFPCre}}$;Prox $1^{+/ \text {Flox }}$ ) showed a similar phenotype to those in standard Prox 1 heterozygous mice, including edema at embryonic stage E14.5, chylous ascites, reduced viability, and reduced ear lymph flow; however, the reduced postnatal viability of these conditional mice makes it very difficult to have access to a significant number of adult mice. We believe that this reduced viability is because the Lyve $1^{+/ G F P C r e}$ strain used for these crosses is not yet in the pure NMRI background necessary for Prox $1^{+/-}$ mouse survival. Importantly, we also showed that restoring Prox1 levels in Prox1 ${ }^{+/}$LECs was sufficient to

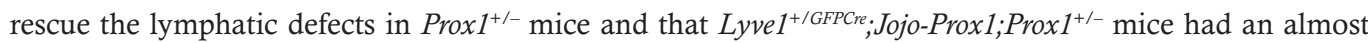
normal neonatal survival rate, did not exhibit chylous ascites, and were less obese than Prox $1^{+/-}$littermates.

To explain the restoration of lymphatic function in these animals, we propose a couple of alternative possibilities. Lyve-1 is expressed initially in the cardinal vein (prior to Prox1 expression), the source from 

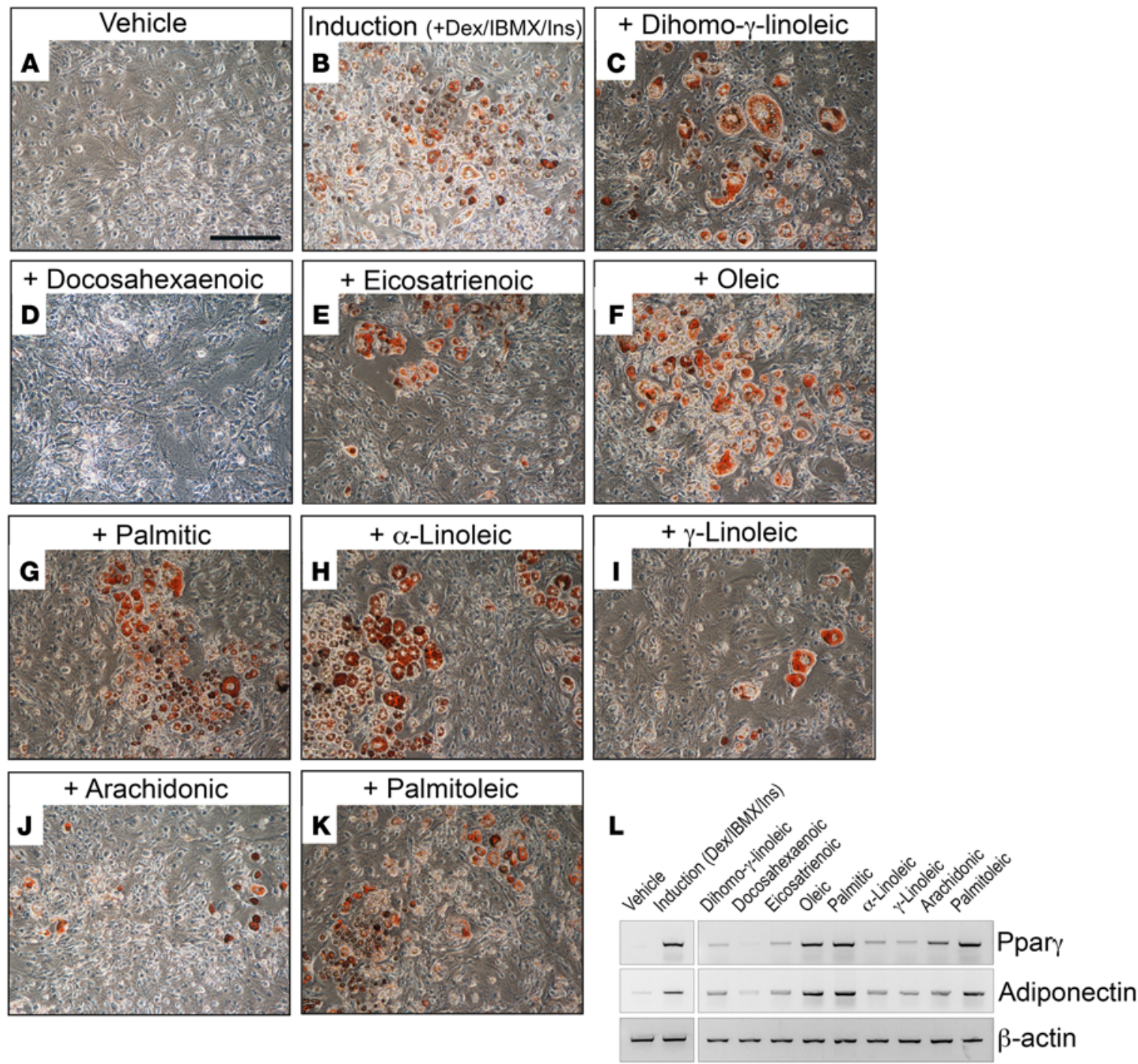

Figure 6. Lipids are the adipogenic stimulus in chyle. (A and B) 3T3-L1 preadipocytes in control culture media plus vehicle (A) and culture media containing dexamethasone (Dex), 3-isobuty-1-methylxanthine (IBMX), and insulin (Ins) (B). The adipocyte indicator Oil Red O (red) was used to show differentiated adipocytes. (C-K) In vitro adipogenic studies of 3T3-L1 preadipocytes showed Oil Red 0 accumulation after treatment with $10 \mu \mathrm{M}$ of various fatty acids for 2 days in the absence of dexamethasone, IBMX, and insulin during the induction phase, followed by 6 days in progression media (DMEM plus $5 \%$ fetal bovine serum plus $1.5 \mu \mathrm{g} / \mathrm{ml}$ insulin). (L) RT-PCR showing expression of Ppar $\gamma$ and adiponectin (indicative of adipocyte differentiation) induced in response to the different lipids tested. $\beta$-Actin was used as a loading control. Scale bar: $100 \mu \mathrm{m}$.

which most Prox1-expressing LEC progenitors will be specified $(39,40)$. As these LECs emerge from the vein, Lyve-1 expression is maintained at higher levels in most lymphatic vessels and macrophages. Thus, one could argue that the rescue of lymphatic function is the consequence of an increased number of LEC progenitors forming in the cardinal vein and/or it is the consequence of Prox1 in LECs in the lymphatic vasculature being restored to levels that are comparable to those in LECs of WT mice.

Independent of the mechanism, this result is relevant, as it provides in vivo conclusive proof that lymphatic malfunction is ultimately responsible for the obesity phenotype of $\mathrm{Prox}^{1^{+-}}$mice as well as strong evidence that links lymphatic function and adipocytes. It also shows that Prox1 thresholds are important for maintaining lymphatic vessel integrity, as our data also suggest that haploinsufficiency of Prox 1 affects and disrupts the connections between endothelial cells, thereby causing lymph leakage. This result is supported by the recent findings by Sawane et al. (41), who proposed a new treatment of obesity that is based on reinforcing lymphatic and blood vessel integrity with apelin, a molecule highly expressed in endothelial cells. Apelin-knockout mice fed a HFD for 5 weeks have an obesity phenotype associated with abnormal 
lymphatic vasculature, enlarged blood vasculature, and increased leakiness. Interestingly, apelin-transgenic mice are resistant to obesity and show decreased subcutaneous adipose tissue that is attributable to inhibition of HFD-induced hyperpermeability of vessels (41).

Additional evidence linking lymphatic dysfunction and obesity can be derived from published studies. For example, Chy mice carrying a heterozygous mutation in the tyrosine kinase domain of Vegfr 3 exhibit early developmental defects associated with malfunction of the lymphatics and abnormal subcutaneous fat deposition $(42,43)$. Dermal and subdermal lipid accumulation is another feature of lymphedema (17, $43,44)$ that is most likely a consequence of defective lymphatic clearance of interstitial lipids $(7,43)$. A human case report by Tavakkolizadeh et al. (45) presented a patient with congenital cutaneous lymphatic malformation that became more pronounced during adolescence and resulted in fat hypertrophy at the site of the lymphatic malformation during adulthood. Furthermore, localized lymphatic dysfunction can result in abnormal accumulation of fat in the nearby tissues. For example, acquired lymphedema resulting from surgical resection of axillary lymph nodes in patients with breast cancer leads to accumulation of lymph in the arm, followed by subcutaneous adipose tissue accumulation in a nearby region $(14,46$, 47). Schirger et al. reported in 1962 that surgically extirpated skin and subcutaneous tissues from patients with chronic lymphedema show similar pathologic changes: "the subcutaneous fat was strikingly abundant in all cases" (44).

Transcription factor forkhead box protein $\mathrm{C} 2$ ( $F O X C 2)$, a gene required for formation and maturation of collecting vessels, provides evidence in humans that links a genetic lymphatic defect with obesity (48). Mutations in FOXC2 cause a major form of hereditary lymphedema, lymphedema-distichiasis syndrome (49). In 2003, Kovacs et al. (50) found a single nucleotide polymorphism (SNP) in the putative promoter region of FOXC2 that was associated with body mass index (BMI) and percentage of body fat in Pima subjects, a group of Native Americans. In agreement with these findings, 2 years later, a case-control study found the same association between this polymorphism in FOXC2 and increased BMI in Scandinavian patients, in whom FOXC2 is consistently associated with obesity and features of dysmetabolic syndrome (51). Furthermore, transgenic mice overexpressing FoxC2 display a reduction in the amount and size of white adipose tissue under conditions of normal or HFD regimens (52), suggesting that gain of function of FoxC2 counteracts obesity features.

In line with our findings, new results in humans support $P R O X 1$ as a strong candidate associated with obesity. For example, a family-based, genome-wide association study combined with a genome-wide linkage study in Mongolian and Korean individuals identified a SNP in proximity to PROX1 that is associated with increased waist circumference (53). Additionally, a recent clinical study hinted that the phenotype described in Prox $1^{+/-}$mice could have counterparts in humans. In fact, individuals of Polish origin with obesity features have a SNP (rs340874) in the 5'-UTR region of PROX1 (54), and this SNP is mutated in some obese patients. The BMI did not differ among the obese subjects; however, individuals carrying the mutation in the PROX1 SNP had higher levels of nonesterified fatty acids after a high-fat meal, lower glucose oxidation after high-carbohydrate meal, and higher accumulation of visceral fat but, surprisingly, lower daily food consumption.

In summary, these data support the idea that some type of "crosstalk" occurs between the lymphatic vasculature and adipose tissue. This could be mediated in different ways, depending on the tissue and the animal model, but, eventually, the outcome is the same - a defective lymphatic vasculature, leading to fat accumulation. Here, we provide conclusive evidence that in more severe circumstances in which the extent of lymphatic malfunction is more extensive but remains asymptomatic (no edema), the subtle leakage of chyle is sufficient to trigger de novo adipogenesis and ultimately obesity, at least in the animal model that we analyzed. In agreement with previous findings (55), it is most likely that, as the animals or individuals become heavier, lymphatic function worsens creating a vicious cycle.

Previous extensive work has emphasized that diet-induced obesity has the capacity to remodel and impair the function of the lymphatic vasculature. For example, diet-induced obesity in WT animals significantly impairs their lymphatic system, as reflected by decreased lymph flow, changes in lymph node architecture, impaired migration of dendritic cells to draining lymph nodes (25), and an increased propensity to inflammation (26). Additionally, a HFD is associated with impaired collecting lymphatic vessel function, as evidenced by a reduced frequency of contractions and diminished response to mechanostimulation (24). Clinical reports also support these findings. For example, in 2012, Greene et al. (55) reported 15 cases of obese patients with BMIs higher than 30 and no history of primary lymphedema. The average BMI of 
the patients with lymphedema was significantly greater than that of obese patients without lymphedema (mean BMI $=70.1$ vs. 40.0) (55). A recent retrospective review of patients who had a BMI greater than 60 but reduced it to less than 50 showed that only some patients had lymphedema, suggesting that weight loss might reverse some instances of obesity-induced lymphedema (56). Moreover, lymphatic drainage from adipose tissue is slower in obese patients (27).

These findings argue for reciprocal regulation: genetic malformation of lymphatics leads to enhanced adipose tissue accumulation, and diet-induced obesity is associated with acquired lymphatic dysfunction. Nevertheless, the cellular mechanism regulating this mutual regulation remains poorly understood. On the basis of our results, we can speculate that free fatty acids released by defective lymphatics in Prox $1^{+/-}$mice cause fat to accumulate. We demonstrated that lymph contains lipid factors capable of inducing adipogenesis in vitro, regardless of whether the mouse is WT or Proxl ${ }^{+/}$. The concept of free fatty acids causing adipocyte differentiation is not a new one. In fact, oleic acid and linoleic acid cause 3T3-L1 cell differentiation $(57,58)$ and might contribute to the maturation of adipocytes. According to previous findings, chronic inflammation induces permanent enlargement in adipocytes that are associated anatomically and metabolically with activated lymphoid tissues (59); therefore, similar mechanisms might operate locally in the maturation of adipocytes induced by free fatty acids contributing to the long-term obesity. These results have clinical implications for the care and treatment of patients suffering from chylous efflux whose treatment options include nutritional intervention, such as an essentially fat-free diet $(60,61)$. Furthermore, in patients with adult-onset obesity and/or secondary lymphedema, limiting the intake of these adipogenic lipids may diminish their detrimental effects.

In conclusion, we have previously shown that haploinsufficiency of Prox 1 impairs the lymphatic vasculature at the functional and structural levels, thereby compromising its integrity (7). We now demonstrate that this defect can lead to obesity as a consequence of the subtle leakage of lymph into the surrounding tissues, in which adipogenic free fatty acids promote adipogenesis, thus initiating obesity. This is a slow, subtle process that becomes more evident as individuals age. Our data strongly argue that a defective lymphatic vasculature promotes adipose deposition and thus is a risk factor for obesity.

\section{Methods}

Mice. Lyve1 ${ }^{+/ G F P C r e}$ mice were obtained from the Jackson Laboratory (stock no. 012601) (31) and were backcrossed to NMRI background for at least 6 generations. Prox $1^{+/-}\left(\right.$Prox $^{+/ \text {LacZ }}$, Prox $\left.1^{+/ \text {GFPCre }}\right)$ mice have been reported previously $(62,63)$. $L e p^{o b / o b}$ mice (referred to as $o b / o b$ mice herein) were also obtained from the Jackson Laboratory and backcrossed to the NMRI background. Prox $1^{+/ F l o x}$ and Jojo-Prox 1 mice have been described previously $(7,33,34)$.

Lymphatic clearance from ear tissue. Lymphatic vessel drainage function was assessed by measuring the clearance over time after injection of P20D800 into mouse ears as previously described (22). Mice were anesthetized with isoflurane (2\%), and $3 \mu \mathrm{l}$ of $3 \mu \mathrm{mol} / 1$ P20D800 was injected into the ears with a 29-gauge insulin syringe (Terumo). The mice were then positioned in an IVIS spectrum (Caliper Life Sciences), and an image was acquired with the following settings: ex: $745 \mathrm{~nm}$, em: $800 \mathrm{~nm}$, binning of 2, exposure time of 2 seconds. Subsequent images of the ears were acquired at 1, 2, 4, 6, and 24 hours after injection. Mice were allowed to wake up and move freely between time points.

Noninvasive NIR imaging of afferent collecting lymphatic vessels. NIR imaging of lower limb collecting lymphatic vessels using the lymphatic-specific tracer P20D680 was performed as previously described $(22,23)$. In brief, a Zeiss StereoLumar.V12 microscope adapted for NIR visualization was used to acquire videos to assess lymphatic perfusion during injection of $5 \mu \mathrm{l}$ of $20 \mu \mathrm{mol} / 1$ P20D680 into dorsal skin of the rear paw. Additional videos to visualize the contractility of afferent lymphatic vessels of the popliteal lymph node were recorded before and after mechanostimulation of the paw skin. Mechanostimulation was performed to stimulate initial lymphatic uptake of the tracer and demonstrate the capacity of the lymphatic system to react to a sudden fluid load (24). A region-of-interest analysis of fluorescence intensity was performed to quantify the frequency of collecting lymphatic vessel contractions. The response to mechanostimulation was assessed by determining the fold change in mean fluorescence intensity from a 10 -second period immediately before mechanostimulation to a period 30 to 60 second after mechanostimulation.

Whole-mount immunostaining. Mice were euthanized, and whole ears and the collecting lymphatic vessels from the lower limbs were harvested as previously described $(22,24)$. To analyze the dermal lymphatics, ears were split, and the inside part of the dorsal side of each ear was used for immunostaining. To 
detect the collecting lymphatic vessels of the hind limb, $5 \mu$ Evans blue dye (diluted to 1\% in sterile PBS) was injected intradermally, and the two collectors adjacent to the saphenous vein were manually dissected under a stereoscope. Tissues were flattened using insect pins onto homemade silicon-coated tissue culture plates and fixed in 4\% PFA diluted in PBS for 2 hours. Then, tissues were washed in PBS and blocked in blocking buffer ( $5 \%$ normal donkey serum, $1 \%$ BSA, $0.1 \%$ Triton $\mathrm{X}-100$, and $0.05 \% \mathrm{NaN}_{3}$ ) for 2 hours at room temperature and incubated over night with the primary antibody mix diluted in blocking buffer under rotation (rat anti-Pecam1 [BD Pharmingen, 553370]; guinea pig anti-Lyve-1, ref. 64; mouse anti-SMACy3 [Sigma-Aldrich, C6198]; rabbit anti-ZO-1 [Thermo Fisher Scientific, 40-2200]).

On the next day, samples were extensively washed in PBS- $0.1 \%$ Triton X-100 for 2 hours at room temperature and then incubated with the corresponding secondary conjugated antibody for 2 hours. Finally, the samples were washed with PBS- $0.1 \%$ Triton X-100 for at least 2 hours and mounted on glass slides using Vectashield antifade-mounting medium (VECTOR laboratories). The images were acquired and analyzed using a Leica TCS SPE DM2500 RGB confocal microscope, and Z-stack images were acquired using LAS AF SPE Core software. All images were processed with Adobe Photoshop CS5.1 software.

Measurement of lymph flow in the ear. Mice were anesthetized with $3 \%$ isoflurane, and $3 \mu 1$ of $1 \%$ Evans blue dye solution was injected into each ear via a tuberculin syringe. Pictures of both ears were taken immediately and 24 hours later. Subsequently, the mice were euthanized, and the ears were removed. Evans blue dye was extracted from the ears by incubation for 2 days in $500 \mu 1$ of formamide at $55^{\circ} \mathrm{C}$ with gentle, constant agitation. The amount of extravasated dye was determined by measuring the absorbance at 620 $\mathrm{nm}$ on a Synery2 (Biotek) microplate reader, as previously described (30-32). The concentration of dye was calculated using a standard curve of known Evans blue dye concentrations in formamide. Data are presented as the amount $(\mu \mathrm{M})$ of dye that remained in the whole ear skin.

Chyle fractionation and lipid profiling analysis. Chyle samples were heat inactivated by heating for $30 \mathrm{~min}$ utes at $95^{\circ} \mathrm{C}$. Proteins were destroyed by adding an equal volume of trypsin-EDTA (Gibco) for 30 minutes at $37^{\circ} \mathrm{C}$, followed by heating at $95^{\circ} \mathrm{C}$, or by pepsin digestion for 30 minutes at $37^{\circ} \mathrm{C}$ followed by heating at $95^{\circ} \mathrm{C}$ for 30 minutes. Chyle was fractionated into crude protein and lipid fractions using the Bligh-Dyer lipid extraction method. Then, the organic phase (lipid fraction) was evaporated and resuspended in $1 \mathrm{ml}$ hexane (Fisher). The hexane-based lipid fraction was then separated into lipid classes by elution on a 300 $\mathrm{mg} \mathrm{NH} \mathrm{N}_{2}$-propyl solid phase extraction (SPE) cartridge (Alltech). The fractions were resuspended in DMSO for in vitro adipocyte differentiation assays. Lipid profiling was performed on lymph obtained from adult WT and Prox $1^{+/-}$mice. Three biological samples for each genotype were pooled together for gas and liquid chromatography followed by mass spectrometry at the Core Facility for Mass Spectometry, Medical University of Graz (Austria).

3T3-L1 cell culture, differentiation, and treatment. The 3T3-L1 cells were purchased from ATCC (CL-173) and maintained in culture per ATCC's recommendations. Briefly, cells were grown in Dulbecco's Modified Eagle's Medium (DMEM) supplemented with 5\% fetal bovine serum, glutamine, and penicillin/streptomycin (standard culture media) in a $5 \% \mathrm{CO}_{2}$ environment. To control adipocyte differentiation, 3T3-L1 cell differentiation was induced by maintaining the cells in culture media supplemented with $0.5 \mathrm{mM}$ 3-isobuty-1-methylxanthine (IBMX), $1.0 \mu \mathrm{M}$ dexamethasone, and $1.5 \mu \mathrm{g} / \mathrm{ml}$ insulin for 2 days (induction phase). Then, the cells were placed in a progression media containing the standard culture media plus $1.5 \mu \mathrm{g} / \mathrm{ml}$ insulin for another 6 days (progression phase); the progression medium was replaced every 2 days. As negative controls, cells in regular media were maintained for the same time period.

Lymph was collected by cannulation of the thoracic duct from adult WT and Prox $1^{+/-}$littermates and tested for differences in capacity to promote adipogenesis. Lymph fluid from each genotype was added to separate standard culture media at different concentrations $(4,8$, and $16 \mu 1 / \mathrm{ml})$ during the induction period. Later, cells were changed to progression media for 6 days. Adipocyte differentiation, which was monitored daily by microscopy, was manifest by the accumulation of intracellular lipid drops.

To determine the adipogenic capacity of free fatty acids, differentiation was induced by adding the following purified fatty acids: dihomo- $\gamma$-linoleic acid, docosahexaenic acid, palmitic acid, arachidonic acid, $\alpha$-linoleic acid, $\gamma$-linoleic acid, oleic acid, palmitoleic acid, or eicosatrienoic acid (all from Cayman Chemical Company). Each fatty acid was added to the regular media during the induction phase (in absence of IBMX/dexamethasone/insulin) at a final concentration of 10 or $20 \mu \mathrm{M}$ and incubated for 2 days. Then, cells were allowed to grow for 6 days in the progression media. As a control, an equivalent volume of vehicle (ethanol) was added to the regular media during the 2-day induction phase. 
To determine the degree of differentiation at the end of the progression phase (day 8), cells were fixed with 4\% paraformaldehyde, washed in PBS, stained with Oil Red O (Sigma-Aldrich), washed again with PBS and then finally with $\mathrm{dH}_{2} \mathrm{O}$, allowed to dry, and observed under a bright-field microscope as described previously (7). To determine adipocyte differentiation, RT-PCR was performed. Total RNA was extracted with the RNeasy Mini Kit (QIAGEN) according to the manufacturer's instructions. Reverse transcription was performed on $1 \mu \mathrm{g}$ total RNA by using the Advantage RT-for-PCR Kit (Clontech) per the manufacturer's instructions. Then, PCR was performed using specific primers for Ppar $\gamma$, adiponectin, and $\beta$-actin, as previously described (7). All experiments were performed in triplicate.

Statistics. Data analyses and statistical analyses were performed using Prism 5 software (Graph Pad Software Inc.). Values are presented as the group mean \pm SEM. Means of 2 groups were compared using unpaired 2-tailed $t$ test (Figures 1-3 and Supplemental Figure 3). For statistical analyses in Figure 5, we used 1-way ANOVA followed by Bonferroni's multiple comparison test. $P$ values less than 0.05 were considered statistically significant.

Study approval. All animal procedures and experiments were performed in accordance with protocols approved by the Institutional Animal Care and Use Committee at St. Jude Children's Research Hospital and by the Kantonales Veterinäramt Zürich.

\section{Author contributions}

NE, STP, and SK designed research, performed research, and analyzed data. MED participated in the performance of the study and mouse strains maintenance. NJ performed most of the in vitro analysis. MD contributed with essential reagents/analysis tools and, together with STP and SK, revised and commented on the manuscript. GO participated in the design of the study, supervised the project, and, together with NE, wrote the manuscript.

\section{Acknowledgments}

We thank Angela McArthur for scientific editing of this manuscript, Ginger Redd for her assistance with collecting blood samples, and Steffen Massberg for collecting lymph from WT and Prox $1^{+-}$adult mice. This work was supported by NIH grant R01-HL073402 (to G. Oliver), the Leducq Foundation Transatlantic Networks of Excellence "Lymph Vessels in Obesity and Cardiovascular Disease" grant 11CVD03 (to M. Detmar and G. Oliver), American Lebanese Syrian Associated Charities (to G. Oliver), Swiss National Science Foundation grant 310030B_147087 (to M. Detmar), and European Research Council grant LYVICAM (to M. Detmar).

Address correspondence to: Guillermo Oliver, Northwestern University Feinberg School of Medicine, 303 East Superior Street, 10-107, Chicago, Illinois 60611, USA. Phone: 312.503.1651; E-mail: guillermo. oliver@northwestern.edu.

Guillermo Oliver's present address is: Center for Vascular and Developmental Biology, Northwestern University Feinberg School of Medicine, Chicago, Illinois, USA.

1. Rockson SG. Lymphedema. Am J Med. 2001;110(4):288-295.

2. Witte MH, Bernas MJ, Martin CP, Witte CL. Lymphangiogenesis and lymphangiodysplasia: from molecular to clinical lymphology. Microsc Res Tech. 2001;55(2):122-145.

3. Greene AK, Maclellan RA. Obesity-induced upper extremity lymphedema. Plast Reconstr Surg Glob Open. 2013;1(7):e59.

4. Aschen S, Zampell JC, Elhadad S, Weitman E, De Brot M, Mehrara BJ. Regulation of adipogenesis by lymphatic fluid stasis: part II. Expression of adipose differentiation genes. Plast Reconstr Surg. 2012;129(4):838-847.

5. Chakraborty S, Zawieja S, Wang W, Zawieja DC, Muthuchamy M. Lymphatic system: a vital link between metabolic syndrome and inflammation. Ann N Y Acad Sci. 2010;1207(suppl 1):E94-E102.

6. Rockson SG. Causes and consequences of lymphatic disease. Ann N Y Acad Sci. 2010;1207(suppl 1):E2-E6

7. Harvey NL, et al. Lymphatic vascular defects promoted by Prox1 haploinsufficiency cause adult-onset obesity. Nat Genet. 2005;37(10):1072-1078.

8. World Health Organization. Global Status Report On Noncommunicable Diseases 2014. Geneva, Switzerland: WHO; 2014

9. Mokdad AH, Marks JS, Stroup DF, Gerberding JL. Actual causes of death in the United States, 2000. JAMA. 2004;291(10):1238-1245.

10. Greenberg AS, Obin MS. Obesity and the role of adipose tissue in inflammation and metabolism. Am J Clin Nutr. 2006;83(2):461S-465S. 
11. Hill SE, et al. Differences in obesity among men of diverse racial and ethnic background. Am J Mens Health. 2015;9:1557988315580348.

12. Dixon JB. Lymphatic lipid transport: sewer or subway?. Trends Endocrinol Metab. 2010;21(8):480-487.

13. Wang Y, Oliver G. Current views on the function of the lymphatic vasculature in health and disease. Genes Dev. 2010;24(19):2115-2126.

14. Brorson H. From lymph to fat: liposuction as a treatment for complete reduction of lymphedema. Int J Low Extrem Wounds. 2012;11(1):10-19.

15. Rosen ED. The molecular control of adipogenesis, with special reference to lymphatic pathology. Ann N Y Acad Sci. 2002;979:143-158.

16. Mortimer PS, Rockson SG. New developments in clinical aspects of lymphatic disease. J Clin Invest. 2014;124(3):915-921.

17. Lim HY, et al. Hypercholesterolemic mice exhibit lymphatic vessel dysfunction and degeneration. Am J Pathol. 2009;175(3):1328-1337.

18. Lim HY, et al. Lymphatic vessels are essential for the removal of cholesterol from peripheral tissues by SR-BI-mediated transport of HDL. Cell Metab. 2013;17(5):671-684.

19. Bilancini S, Lucchi M, Tucci S, Eleuteri P. Functional lymphatic alterations in patients suffering from lipedema. Angiology. $1995 ; 46(4): 333-339$.

20. Shin BW, Sim YJ, Jeong HJ, Kim GC. Lipedema, a rare disease. Ann Rehabil Med. 2011;35(6):922-927.

21. Proulx ST, et al. Non-invasive dynamic near-infrared imaging and quantification of vascular leakage in vivo. Angiogenesis. 2013;16(3):525-540.

22. Karaman S, et al. Decline of lymphatic vessel density and function in murine skin during aging. Angiogenesis. 2015;18(4):489498.

23. Proulx ST, et al. Use of a PEG-conjugated bright near-infrared dye for functional imaging of rerouting of tumor lymphatic drainage after sentinel lymph node metastasis. Biomaterials. 2013;34(21):5128-5137.

24. Blum KS, et al. Chronic high-fat diet impairs collecting lymphatic vessel function in mice. PLoS One. 2014;9(4):e94713.

25. Weitman ES, et al. Obesity impairs lymphatic fluid transport and dendritic cell migration to lymph nodes. PLoS One. 2013;8(8):e70703.

26. Savetsky IL, et al. Obesity increases inflammation and impairs lymphatic function in a mouse model of lymphedema. Am $J$ Physiol Heart Circ Physiol. 2014;307(2):H165-H172.

27. Arngrim N, Simonsen L, Holst JJ, Bülow J. Reduced adipose tissue lymphatic drainage of macromolecules in obese subjects: a possible link between obesity and local tissue inflammation? Int J Obes (Lond). 2013;37(5):748-750.

28. Lindström P. The physiology of obese-hyperglycemic mice [ob/ob mice]. ScientificWorldJournal. 2007;7:666-685

29. Pham TH, et al. Lymphatic endothelial cell sphingosine kinase activity is required for lymphocyte egress and lymphatic patterning. J Exp Med. 2010;207(1):17-27.

30. Nouvion AL, et al. CEACAM1: a key regulator of vascular permeability. J Cell Sci. 2010;123(pt 24):4221-4230.

31. Huggenberger R, et al. An important role of lymphatic vessel activation in limiting acute inflammation. Blood. 2011;117(17):4667-4678.

32. Phung TL, et al. Pathological angiogenesis is induced by sustained Akt signaling and inhibited by rapamycin. Cancer Cell. 2006;10(2):159-170.

33. Lavado A, Lagutin OV, Chow LM, Baker SJ, Oliver G. Prox1 is required for granule cell maturation and intermediate progenitor maintenance during brain neurogenesis. PLoS Biol. 2010;8(8):e1000460.

34. Srinivasan RS, Oliver G. Prox1 dosage controls the number of lymphatic endothelial cell progenitors and the formation of the lymphovenous valves. Genes Dev. 2011;25(20):2187-2197.

35. Flier JS. Obesity wars: molecular progress confronts an expanding epidemic. Cell. 2004;116(2):337-350.

36. Cardenas A, Chopra S. Chylous ascites. Am J Gastroenterol. 2002;97(8):1896-1900.

37. Yoon MS, Zhang C, Sun Y, Schoenherr CJ, Chen J. Mechanistic target of rapamycin controls homeostasis of adipogenesis. $J$ Lipid Res. 2013;54(8):2166-2173.

38. Bligh EG, Dyer WJ. A rapid method of total lipid extraction and purification. Can J Biochem Physiol. 1959;37(8):911-917.

39. Wigle JT, et al. An essential role for Prox1 in the induction of the lymphatic endothelial cell phenotype. EMBO J. 2002;21(7):1505-1513

40. Gordon EJ, Gale NW, Harvey NL. Expression of the hyaluronan receptor LYVE-1 is not restricted to the lymphatic vasculature; LYVE-1 is also expressed on embryonic blood vessels. Dev Dyn. 2008;237(7):1901-1909.

41. Sawane M, et al. Apelin inhibits diet-induced obesity by enhancing lymphatic and blood vessel integrity. Diabetes. 2013;62(6):1970-1980

42. Karkkainen MJ, et al. A model for gene therapy of human hereditary lymphedema. Proc Natl Acad Sci U S A. 2001;98(22):12677-12682

43. Rutkowski JM, et al. Dermal collagen and lipid deposition correlate with tissue swelling and hydraulic conductivity in murine primary lymphedema. Am J Pathol. 2010;176(3):1122-1129.

44. Schirger A, Harrison EG Jr, Janes JM. Idiopathic lymphedema. Review of 131 cases. JAMA. 1962;182:14-22.

45. Tavakkolizadeh A, Wolfe KQ, Kangesu L. Cutaneous lymphatic malformation with secondary fat hypertrophy. Br J Plast Surg. 2001;54(4):367-369.

46. Brorson $\mathrm{H}$. Adipose tissue dominates chronic arm lymphedema following breast cancer: an analysis using volume rendered CT images. Lymphat Res Biol. 2006;4(4): 199-210.

47. Brorson H. From lymph to fat: complete reduction of lymphoedema. Phlebology. 2010;25(suppl 1):52-63.

48. Norrmén C, et al. FOXC2 controls formation and maturation of lymphatic collecting vessels through cooperation with NFATc1. J Cell Biol. 2009;185(3):439-457.

49. Dagenais SL, et al. Foxc2 is expressed in developing lymphatic vessels and other tissues associated with lymphedema-distichiasis syndrome. Gene Expr Patterns. 2004;4(6):611-619.

50. Kovacs P, Lehn-Stefan A, Stumvoll M, Bogardus C, Baier LJ. Genetic variation in the human winged helix/forkhead transcrip- 
tion factor gene FOXC2 in Pima Indians. Diabetes. 2003;52(5):1292-1295.

51. Carlsson E, Groop L, Ridderstråle M. Role of the FOXC2 -512C >T polymorphism in type 2 diabetes: possible association with the dysmetabolic syndrome. Int J Obes (Lond). 2005;29(3):268-274

52. Cederberg A, et al. FOXC2 is a winged helix gene that counteracts obesity, hypertriglyceridemia, and diet-induced insulin resistance. Cell. 2001;106(5):563-573.

53. Kim HJ, et al. Combined linkage and association analyses identify a novel locus for obesity near PROX1 in Asians. Obesity (Silver Spring). 2013;21(11):2405-2412.

54. Lecompte S, et al. Genetic and molecular insights into the role of PROX1 in glucose metabolism. Diabetes. 2013;62(5):17381745 .

55. Greene AK, Grant FD, Slavin SA. Lower-extremity lymphedema and elevated body-mass index. $N$ Engl J Med. 2012;366(22):2136-2137.

56. Greene AK, Slavin SA, Brorson H, eds. Lymphedema: Presentation, Diagnosis, And Treatment. London, United Kingdom: Springer International Publishing Switzerland; 2015.

57. Kokta TA, et al. Regulation of lipid accumulation in 3T3-L1 cells: insulin-independent and combined effects of fatty acids and insulin. Animal. 2008;2(1):92-99.

58. Loo LH, Lin HJ, Singh DK, Lyons KM, Altschuler SJ, Wu LF. Heterogeneity in the physiological states and pharmacological responses of differentiating 3T3-L1 preadipocytes. J Cell Biol. 2009;187(3):375-384.

59. Sadler D, Mattacks CA, Pond CM. Changes in adipocytes and dendritic cells in lymph node containing adipose depots during and after many weeks of mild inflammation. J Anat. 2005;207(6):769-781.

60. Chen FP, Lo TS, Soong YK. Management of chylous ascites following laparoscopic presacral neurectomy. Hum Reprod. 1998;13(4):880-883.

61. Chen E, Itkin M. Thoracic duct embolization for chylous leaks. Semin Intervent Radiol. 2011;28(1):63-74.

62. Wigle JT, Oliver G. Prox1 function is required for the development of the murine lymphatic system. Cell. 1999;98(6):769-778

63. Srinivasan RS, et al. The nuclear hormone receptor Coup-TFII is required for the initiation and early maintenance of Prox 1 expression in lymphatic endothelial cells. Genes Dev. 2010;24(7):696-707.

64. Yang Y, et al. Lymphatic endothelial progenitors bud from the cardinal vein and intersomitic vessels in mammalian embryos. Blood. 2012;120(11):2340-2348. 